\title{
Educação e propaganda sanitárias: desdobramentos da formação de um sanitarista brasileiro na Fundação Rockefeller
}

\author{
Education and health propaganda: repercussions of a \\ Brazilian sanitarian's training at the Rockefeller Foundation
}

\author{
Ricardo dos Santos \\ Batista $^{i}$ \\ 1 Professor, Programa de \\ Pós-graduação em História/ \\ Universidade do Estado da Bahia. \\ Alagoinhas - BA - Brasil \\ orcid.org/0000-0002-7959-5929 \\ kadobatista@hotmail.com
}

Recebido em 16 nov. 2017. Aprovado em 29 jun. 2018.
BATISTA, Ricardo dos Santos. Educação e propaganda sanitárias: desdobramentos da formação de um sanitarista brasileiro na Fundação Rockefeller. História, Ciências, Saúde - Manguinhos, Rio de Janeiro, v.26, n.4, out.-dez. 2019, p.1189-1202.

\begin{abstract}
Resumo
O artigo discute a influência da formação de jovens sanitaristas na Fundação Rockefeller para as ações que desenvolveram nos cargos de chefia sanitária no Brasil. São apresentados os métodos de educação e propaganda sanitárias da instituição norte-americana e os cartazes elaborados sob orientação do médico Antônio Luis Cavalcanti de Albuquerque de Barros Barreto na Reforma Sanitária da Bahia. Após retornar da Universidade Johns Hopkins, em Baltimore, onde foi bolsista da Rockefeller entre 1921 e 1922, o médico contribuiu para a difusão nacional dos conhecimentos adquiridos internacionalmente.

Palavras-chave: Fundação Rockefeller; educação sanitária; propaganda sanitária.

Abstract

This article discusses the influence that training at the Rockefeller Foundation had on the activities early-career professionals carried out in health leadership positions in Brazil. We present methods of education and health propaganda at this American institution, as well as posters prepared at the direction of the physician Antonio Luis Cavalcanti de Albuquerque de Barros Barreto during the health reform in Bahia. After returning from the Johns Hopkins University in Baltimore, where he received a Rockefeller Foundation fellowship in 1921-1922, this doctor helped to distribute the knowledge he acquired abroad throughout Brazil.
\end{abstract}

Keywords: Rockefeller Foundation; health education; health propaganda.

http://dx.doi.org/10.1590/S0104-59702019000400009 
A década de 1920 foi importante para o desenvolvimento da saúde no Brasil. A criação do Departamento Nacional de Saúde Pública (DNSP) e a parceria com a Fundação Rockefeller contribuíram para modificar a realidade de vários estados. Eles caminharam de um modelo de governo que intervinha majoritariamente em momentos de epidemias para outro, que passava a reconhecer a importância de ampliar as ações de saúde de forma mais sistemática e permanente (Hochman, 2012; Benchimol, 2001; Santos, Faria, 2003).

Como parte desse processo, é possível destacar a formação de jovens brasileiros que viajaram para os EUA e estudaram na Universidade Johns Hopkins, primeira instituição educacional apoiada pelo projeto da Rockefeller. Segundo Löwy (2006, p.139-141), havia o objetivo de transferir saberes e habilidades específicas para os países nos quais a fundação atuava, com o intuito de elaborar soluções eficazes para os seus problemas (cf. também Palmer, 2015; Faria, 1995). ${ }^{1}$ Para isso, bolsistas latino-americanos eram enviados com o objetivo de serem convertidos à "ciência da saúde pública" e de se tornarem representantes desse saber em seu país de origem. Um exemplo brasileiro foi o médico Antônio Luis Cavalcanti de Albuquerque de Barros Barreto.

Nascido em Pernambuco, em 1892, ele se matriculou na Faculdade de Medicina do Rio de Janeiro em 1910 e estudou na turma de 1913 do Curso de Aplicação de Manguinhos. A convite de Oswaldo Cruz, continuou trabalhando na Seção de Zoologia do Instituto Oswaldo Cruz (IOC) e se especializou no campo dos helmintos parasitos (Barreto, 18 nov. 1947, p.1). Escreveu a tese de doutoramento intitulada Revisão da família Subulurinae Travassos, 1914 e conviveu com estudiosos da medicina tropical como Lauro Travassos, Carlos Chagas e Adolpho Lutz (Barreto, 1918). Em 1916, fez concurso de provas para assistente do IOC e se classificou entre os melhores. Exerceu esse cargo até 1921, quando foi aprovado no concurso para inspetor do DNSP, em primeiro lugar (Barreto, 18 nov. 1947, p.1).

O envolvimento de Barros Barreto com os ideais sanitários da Fundação Rockefeller ocorreu de forma simultânea à inserção da instituição no Brasil, especialmente pela aproximação que ela estabeleceu com os sanitaristas do IOC. Em 1918, o assistente de Manguinhos publicou uma série de cinco artigos que apresentava a metodologia de erradicação de doenças proposta pelos norte-americanos e, ao mesmo tempo, mostrava os benefícios possíveis aos pernambucanos, caso firmassem uma cooperação internacional (Barreto, 18 nov. 1947, p.6). Em 1919, acompanhou Wenceslao Pareja y Pareja, principal colaborador de Hydeio Noguchi no Equador, e o general Theodore C. Lyster, em uma viagem pelo Nordeste. Segundo Benchimol et al. (2009, p.214), antes dessa viagem, Barros Barreto inspecionou um município em Pernambuco e conduziu o inquérito com olhar atento a transmissores e manifestações de outras doenças, em fina sintonia com os trabalhos que haviam sido recém-publicados por Adolpho Lutz sobre a evolução do Schistosoma mansoni.

O itinerário realizado com os representantes da Fundação Rockefeller, entre março e abril de 1920, incluiu os municípios de Ribeirão Preto e Barreiros, em Pernambuco; Salvador, na Bahia; Aracaju, Maroim, Riachuelo e Laranjeiras, em Sergipe; e Maceió, Vitória, Palmeira dos Índios e Olhos d'Água do Accioly, em Alagoas (Benchimol et al., 2009, p.215). Esse percurso teve significado importante para a trajetória do médico, com a ampliação das relações profissionais internacionais e do interesse em viajar ao exterior. Ele se tornou membro correspondente da Sociedad Médico-Quirúrgica del Guayas (Guayaquil - Equador) (Barreto, 
18 nov. 1947, p.4), a partir da relação estabelecida com Pareja. A atuação de destaque, no Brasil, contribuiu para que se tornasse bolsista da Fundação Rockefeller, entre 6 de setembro de 1921 e 31 de agosto de 1922, ${ }^{2}$ quando esteve nos EUA. ${ }^{3}$

Os norte-americanos pregavam uma medicina voltada para a saúde pública, que realizasse maiores intervenções sociais, em contraposição a uma ciência médica com características individuais. Nesse contexto, educação e propaganda sanitárias adquiriam destaque na disseminação de hábitos higiênicos. Para Antônio de Barros Barreto (1923a, p.1037-1038), a educação sanitária consistia em fazer o indivíduo compreender o papel que podia desempenhar na disseminação de certas doenças; dizer-lhe quais as precauções a seguir, de modo a evitá-las; ensinar-lhe como agir no caso de contraí-las; mostrar-lhe o perigo público que era se tornar uma fonte de infecção e "incutir-lhe na consciência" que era um crime abominável contra a pátria transmitir a doença a seus semelhantes; finalmente, despertar-lhe o senso cívico para obter apoio moral e material, para que ele zelasse pela saúde pública, pelo bem da saúde coletiva e da grandeza da pátria.

Entre as três medidas necessárias para a defesa da saúde coletiva: a legislação, a administração e a educação, o médico afirmava que:

Educação e propaganda têm conseguido entre os Americanos do Norte o que a legislação e administração não lograram conquistar. Isto é fácil de compreender porque é sabido que, em toda a parte, disposições legislativas e providências administrativas são quase sempre percebidas com desagrado e não raro com resistências, enquanto que folhetos de propaganda, conferências e demonstrações práticas sobre o valor de medidas que tenham por fim o bem-estar geral e a saúde do povo não sofrem objeções e são acolhidas com todo interesse e atenção (Barreto, 1923a, p.1038).

Convencido dos efeitos eficazes da educação sanitária, Barros Barreto defendia a utilização de métodos diversificados de propaganda, visto que alguns deles corrigiam as lacunas deixadas pelos outros e os completavam. As formas de realizar a propaganda sanitária eram classificadas em quatro categorias: "métodos empregando a palavra falada", que diziam respeito a conferências e palestras; "processos utilizando a palavra escrita", em folhetos, brochuras, cartazes, artigos em periódicos; "meios recorrendo à impressão visual", constituídos de projeções, cinematógrafos e exposições; e, por fim, "processos mistos", que envolviam conferências acompanhadas de projeções (Barreto, 1923b, p.1103).

A principal característica de todos os métodos era a sua adequação aos indivíduosalvo dos programas de educação. Os meios utilizados pelo método da "palavra falada", por exemplo, deveriam interessar o auditório sem o fatigar. Com o tempo de vinte a trinta minutos, as palestras precisavam ser moldadas em forma e linguagem para idade, sexo e, principalmente, condição social e grau de instrução das pessoas que as assistiam. Recomendava-se que o local fosse acessível, conveniente, e a hora, cômoda. As conferências deviam ser anunciadas com bastante antecedência, e o orador devia ser pontual. Para não abusar da atenção dos ouvintes, o conferencista deveria mesclar sua fala com projeções e exemplos relacionados com o assunto da palestra, o que a tornaria mais agradável (Barreto, 1923b, p.1104).

A palavra escrita era considerada de grande valia em todas as campanhas de educação sanitária, mas menos eficaz que outros métodos devido aos índices de analfabetismo do 
Brasil. Para Barros Barreto, era necessário ter atenção à elaboração do projeto gráfico dos cartazes. As dimensões, a feição artística, o número de palavras e o tipo de letra deveriam ser devidamente estudados, de modo que as peças de propaganda atingissem o objetivo de impressionar sem cair no ridículo. Os cartazes deveriam ser fixados em um lugar digno de atenção. Nessa mesma modalidade, o auxílio prestado pela imprensa leiga era considerado de valor inestimável. Os artigos em jornais não especializados em saúde deveriam ser produzidos por autoridades sanitárias, não poderiam ser muito extensos e se recomendava que fossem escritos em linguagem acessível ao grande público. Em relação à distribuição de impressos, poderia ser realizada por empregados do serviço de Saúde Pública especialmente encarregados dessa tarefa, diretores de fábricas, empresas comerciais, casas de diversão, hospitais, escolas, entre outros (Barreto, 1923b, p.1105).

A impressão visual era considerada o método mais eficaz para atingir os objetivos educacionais, quando aliado à palavra falada. Para tanto, deveria conter legendas explicativas de modo a facilitar a compreensão da figura projetada para as pessoas que estavam longe do conferencista e que, eventualmente, podiam ter dificuldade de ouvi-lo. O tipo das projeções animadas deveria ser escolhido de acordo com o público. Para crianças e adolescentes, por exemplo, a comédia se tornaria mais eficaz, assim como enredos que se desenrolassem no campo poderiam ter melhor acolhida entre os trabalhadores rurais (Barreto, 1923b, p.1106).

Por fim, a combinação de todas essas possibilidades poderia trazer excelentes resultados. Barros Barreto afirmava que, em vários estados da federação norte-americana, como Flórida e Carolina do Norte, automóveis e vagões de estradas de ferro foram especialmente adaptados ao método, com o transporte do pessoal necessário, aparelho de projeção, cartazes e folhetos. A Fundação Rockefeller fez o mesmo na luta contra a tuberculose na França, e carros semelhantes eram usados com muito proveito no Serviço de Profilaxia Rural de Minas Gerais, no Brasil (Barreto, 1923b, p.1107).

A partir dessas proposições, é possível compreender as principais estratégias utilizadas para as campanhas de educação sanitária no projeto da Fundação Rockefeller. Os textos publicados pelo ex-bolsista nos Arquivos Brasileiros de Medicina tinham como objetivo disseminar essa metodologia entre médicos brasileiros, depois da observação, in loco, realizada nos EUA. ${ }^{4}$ Castro Santos e Faria (2006, p.293) afirmam que os médicos do Brasil que se formaram em saúde pública na Universidade Johns Hopkins alargaram os caminhos para o surgimento de um novo modelo de atuação profissional, sustentado na educação sanitária, na prevenção de doenças e na formação de recursos humanos.

Os recursos pictóricos e as fotografias também estiveram presentes nas propagandas de jornais e revistas da primeira metade do século XX, com o intuito de ampliar o conhecimento da população brasileira sobre as consequências de contrair doenças. A propaganda de medicamentos se desenvolveu no país, especialmente durante a década de 1920, junto com o melhoramento das técnicas de produção publicitária. A partir do ideal de modernidade difundido pelas elites, que almejavam o remodelamento do espaço urbano e uma população "sã", os medicamentos, com a utilização de imagens, passaram a ser tratados como uma fortaleza contra as fraquezas e vulnerabilidades do corpo, um estímulo à iniciativa e uma caução para o sucesso (Bueno, Taitelbaum, 2008, p.60). Propagandas de medicamentos para a sífilis na cidade de Salvador, na década de 1920, por exemplo, 
utilizavam figuras de crianças deformadas, acéfalas, "monstros xifópagos", fotografias de portadores de sífilis terciária e gravuras de pessoas que teriam se suicidado devido à doença (Batista, 2017a, p.109-120).

Segundo James Roberto Silva (2009, p.27-28), as fotografias médicas utilizadas em propagandas brasileiras eram registradas pelos profissionais em suas clínicas particulares, hospitais ou serviços públicos e na Santa Casa de Misericórdia. Essas fotos retratavam corpos doentes e eram reproduzidas em revistas especializadas, nas quais os clínicos tornavam públicas as suas observações. O autor afirma que a importância desse tipo de fotografia foi percebida como suporte visual, encarnando em si a carga negativa e estigmatizante das moléstias e de suas possíveis consequências. Nas revistas paulistas e francesas que analisou, encontrou fotografias de doentes, de procedimentos médicos, de instalações sanitárias, radiografias e fotomicrografias de órgãos humanos, esqueletos, doentes com verminoses, crianças com poliomielite, entre outras.

As imagens apresentadas aqui fazem parte dos desdobramentos da formação de Antônio Luis Cavalcanti de Albuquerque de Barros Barreto na Fundação Rockefeller. São cartazes produzidos e utilizados no projeto de Reforma Sanitária da Bahia. Eles integram o Relatório da Subsecretaria de Saúde e Assistência Pública, de 1927 (Barreto, 1928), sob a guarda do setor de Obras Raras da Biblioteca Pública do Estado da Bahia, em Salvador.

De volta ao Brasil, o médico foi designado para a chefia do Serviço de Saneamento Rural do Paraná, em março de 1924, quando João de Barros Barreto, que ocupava esse cargo, afastou-se para também ser bolsista da Fundação Rockefeller. Antônio desenvolveu atividades como viagens de inspeção, reorganização de funcionários dos postos sanitários e realização de palestras sobre educação sanitária. Ele destacava o seu empenho para difundir ampla e profusamente conselhos de higiene entre as populações de diversos municípios, apesar da falta de dinheiro para a compra de equipamentos necessários à ilustração das palestras. Além disso, se tornou redator-chefe dos Arquivos Paranaenses de Medicina. O periódico, que divulgava a medicina experimental e a higiene no estado, se despedia do médico, que não teve tempo de desenvolver o programa apresentado à população do Paraná. Foi rapidamente transferido para a Bahia (Barreto, 1924, p.110-119).

Nesse período, os baianos já contavam com os serviços da Fundação Rockefeller, que iniciou as suas atividades no estado em 1920. Segundo Benchimol (2001, p.115-120), os médicos norte-americanos ingressaram no Brasil junto ao desenvolvimento do movimento sanitarista da segunda década do século XX, e, até 1926, Carlos Chagas estabeleceu acordos de cooperação com a instituição para combater a ancilostomíase, a malária, para o ensino de medicina e de enfermagem. Esse processo não ocorreria sem conflitos, visto que alguns médicos brasileiros se consideravam aptos para resolver as suas próprias questões sanitárias, sem interferência externa.

A divergência se tornou mais evidente com a discussão sobre o método de ataque ao vetor da febre amarela. Os médicos estadunidenses, que buscaram cidades menores do Nordeste para demonstrar sua metodologia, queriam implementar um programa unificado em escala nacional, mesmo com as disparidades de saneamento de cada município. Eles consideravam a fumigação um "jogo de cena" para esconder deficiências da administração pública. Também não eram adeptos da ação antilarvária, pelo fato de esse método não ser objeto de exibição 
pública. Mas, nas cidades do interior da Bahia, passaram a adotar peixes larvófagos ou uma camada de óleo nos depósitos de água, o que despertou fortes reações por parte dos clínicos, que denunciavam a escassez de água potável nos sertões baianos (Benchimol, 2001, p.117)

Ainda em 1923, o diretor do Serviço de Profilaxia Rural na Bahia, Sebastião Barroso, pediu demissão do cargo em um ato público e acusou a Fundação Rockefeller de exceder os limites da sua autoridade e assumir o controle total do programa, introduzir peixes retirados de rios poluídos nos depósitos de água potável, além de realizar inspeções em residências particulares em horas impróprias.

Era necessário encontrar alguém para ocupar o cargo de chefia do Serviço de Profilaxia Rural na Bahia. A figura do jovem Barros Barreto, que frequentou o curso de Aplicação em Manguinhos, tornou-se assistente do IOC, inspetor do DNSP e, posteriormente, bolsista da Fundação Rockefeller, reunia todos os pré-requisitos para conduzir aquele posto com sucesso, inclusive por conciliar os ideais do sanitarismo brasileiro da segunda década do século XX, presentes na sua formação inicial, com o projeto de saúde pública proposto pela instituição estrangeira, causa de controvérsias médicas. Ele havia retornado dos EUA decidido a aplicar um programa de saneamento e de saúde pública no local para o qual fosse designado.

Barros Barreto deu ênfase especial às necessidades técnicas e administrativas naquele estado. Afirmou que, antes da sua chegada, havia três repartições de higiene cujas relações nem sempre mantinham a harmonia e, às vezes, demonstravam-se antagônicas em pontos de vista: a Diretoria Geral de Saúde Pública do Estado, a Diretoria de Higiene e Assistência Municipal e o Serviço Federal de Saneamento Rural, também incumbido de fiscalizar os trabalhos da Comissão de Febre Amarela executados pela Fundação Rockefeller.

O médico foi convidado pelo governador Francisco Marques de Góes Calmon, que também se tornou seu sogro, para assumir os serviços estaduais. Mais tarde, em consequência da nova organização, assumiu a Diretoria de Higiene do Município de Salvador: "Desapareciam 'três higienes', passando a superintendência dos serviços sanitários da Bahia a obedecer uma só orientação: do secretário de Saúde e Assistência Pública" (Barreto, 1928, p.24; ênfase no original). ${ }^{5}$ As ações propostas por ele contaram com completa autonomia técnica, administrativa e financeira, não mais dependentes da Secretaria do Interior, Justiça e Instrução Pública, mas diretamente subordinadas ao governador, pela Subsecretaria de Saúde e Assistência Pública, segundo a lei n.1.811 de 29 de julho de 1925 (Bahia, 2 ago. 1925).

O novo secretário foi o líder de um projeto que envolveu mudanças no âmbito da administração sanitária, construção de estruturas próprias para os órgãos estaduais de saúde, aperfeiçoamento de funcionários e a disseminação de educação e propaganda sanitárias. O registro sistemático desse processo possibilitou a identificação dos cartazes produzidos sob a supervisão do sanitarista e que tinham então a oportunidade de ser publicados. As instâncias de diferentes esferas de saúde (municipal, estadual e nacional) foram orquestradas por um único profissional, que aprendeu nos EUA, entre tantos conhecimentos sobre saúde pública, uma forma minuciosa de documentação das suas realizações.

Em relação à metodologia de produção e guarda de documentação da Fundação Rockefeller, especialmente os arquivos de imagem, Aline Lacerda (2002) faz uma descrição comentada da coleção de fotografias sobre o Brasil, pertencentes ao Rockefeller Archive Center (RAC). A autora demonstra como grande parte desse acervo reflete o interesse inicial da agência norte- 
americana pelas ciências médicas, doenças tropicais e saúde pública no país. As imagens eram peças importantes na sua lógica de funcionamento e foram amplamente produzidas e sistematizadas. O circuito de troca fotográfica entre médicos brasileiros e o escritório central da instituição, em Nova York, não se efetuava aleatoriamente, como uma simples troca de informações visuais ou de remessas de imagens sobre o país (Lacerda, 2002, p.628), mas era fundamental como método de registro e de avaliação das atividades desenvolvidas.

Os cartazes somam um número de 33 (aqui são apresentados apenas 16) e podem ser divididos, de forma geral, em temas como: hábitos higiênicos na gestação e infância, higiene industrial, doenças venéreas e doenças tropicais. A seleção da série teve como critério a demonstração da maior variedade temática possível, visto que as imagens estão agrupadas em um número de quatro, por folha, o que poderia repetir exaustivamente alguns temas e negligenciar outros.

As figuras voltadas para a infância apresentam mães e crianças, com frases como "eu quero leite de mamãe", "exame médico uma vez por mês", "escovar os dentes ao levantar e deitar", além de chamar a atenção para a "boa alimentação" infantil. São imagens como a de um recém-nascido que recebe nitrato de prata no olho e a de uma criança com rosto sereno, que dorme com a janela aberta para manter o quarto arejado. Em um cartaz o bebê chora à espera do leite materno e, em outro, chora no consultório, mas seus pais sorriem com as informações oferecidas pelo médico. Na década de 1920, o controle da maternidade havia se constituído como grande meta pela medicina brasileira. Martha Freire (2009) analisou revistas femininas que veiculavam o pensamento de uma maternidade científica. Ela destacou como os médicos progressistas defendiam a substituição dos padrões considerados "arcaicos" pelos novos padrões higiênicos, enquanto os conservadores insistiam em preservar os valores familiares tradicionais. Estavam todos unidos em torno de uma preocupação declarada em relação à infância e ao destino da nação brasileira.

As figuras sobre doenças venéreas também foram utilizadas. A primeira remete a um dispensário, com homens que conversam do lado de fora. Um rapaz utiliza a mão na boca para cochichar, em alusão à cautela da população ao falar sobre a enfermidade, que estava relacionada às representações sobre a degeneração racial presentes na sociedade brasileira nas três primeiras décadas do século XX. O outro cartaz, com a mesma temática, dá destaque à cabeça de uma criança ao lado de uma foice e a um crânio, na parte superior da peça gráfica, com o intuito de responsabilizar os pais por ceifar a vida dos filhos pela transmissão hereditária da sífilis, que tinha altos índices de incidência no Brasil da década de 1920. Batista (2016, 2017a, 2017b) e Batista, Souza (2015) demonstraram como, na reforma da saúde conduzida por Barros Barreto, a multiplicação de postos sanitários e de dispensários auxiliou nos serviços realizados pela Inspetoria de Profilaxia da Lepra e Doenças Venéreas em Salvador e municípios do interior do estado. Esse processo se deu a partir do acordo realizado com a União para o desenvolvimento de ações também voltadas contra a tuberculose e no campo da higiene infantil. Ainda a esse respeito, um cartaz (não exibido aqui), apresenta a enfermeira visitadora como a "mensageira da saúde". Utilizada em vários programas de combate a doenças no pós-1920 brasileiro, como a sífilis e a tuberculose, essa personagem era considerada, pelo médico, fator exponencial do que ele classificava como "a era da higiene" (Barreto, 1923b, p.1037). 

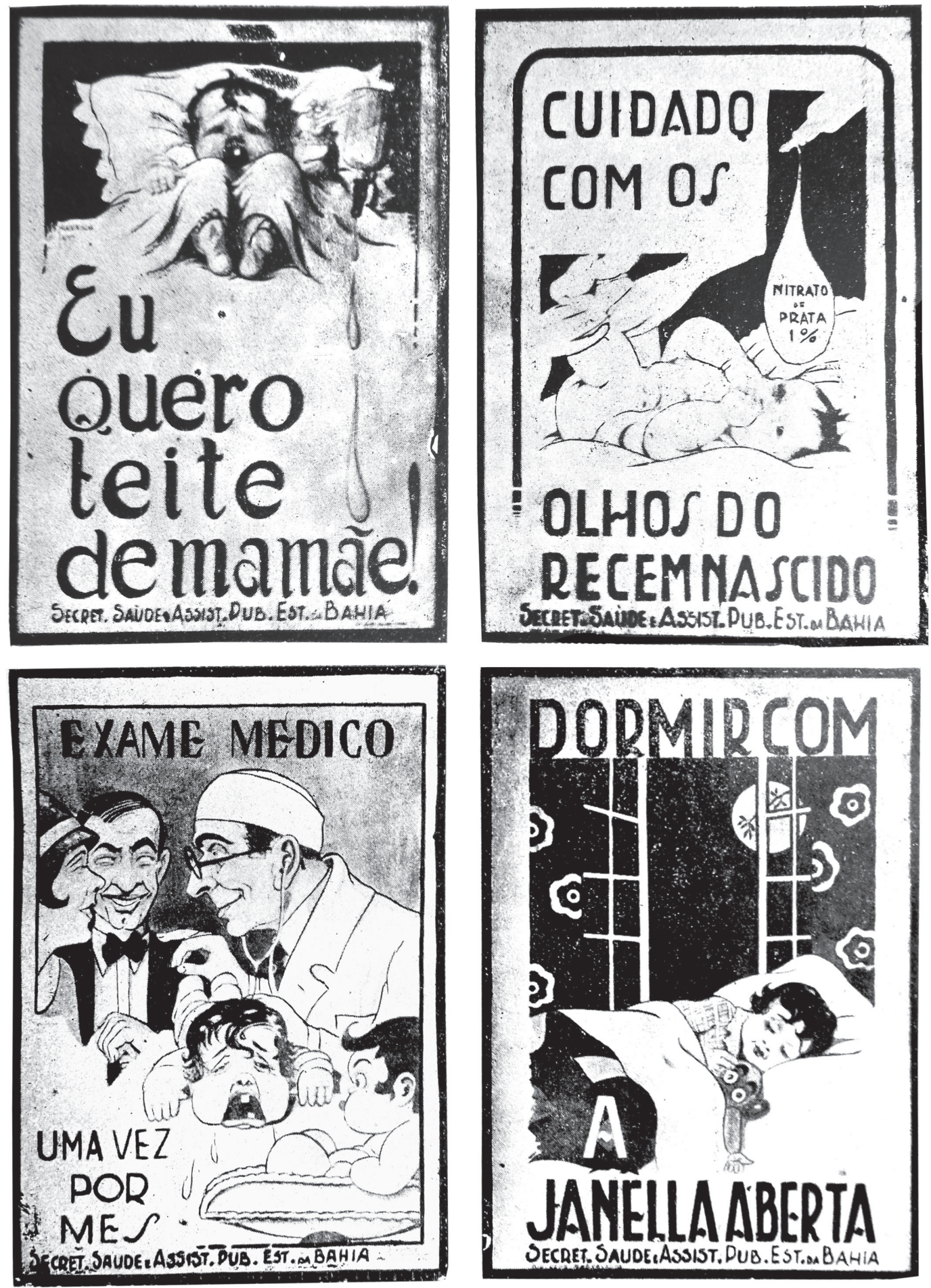

Figura 1: Cartazes de educação sanitária utilizados pela Secretaria de Saúde e Assistência Pública do Estado da Bahia (Barreto, 1928) 

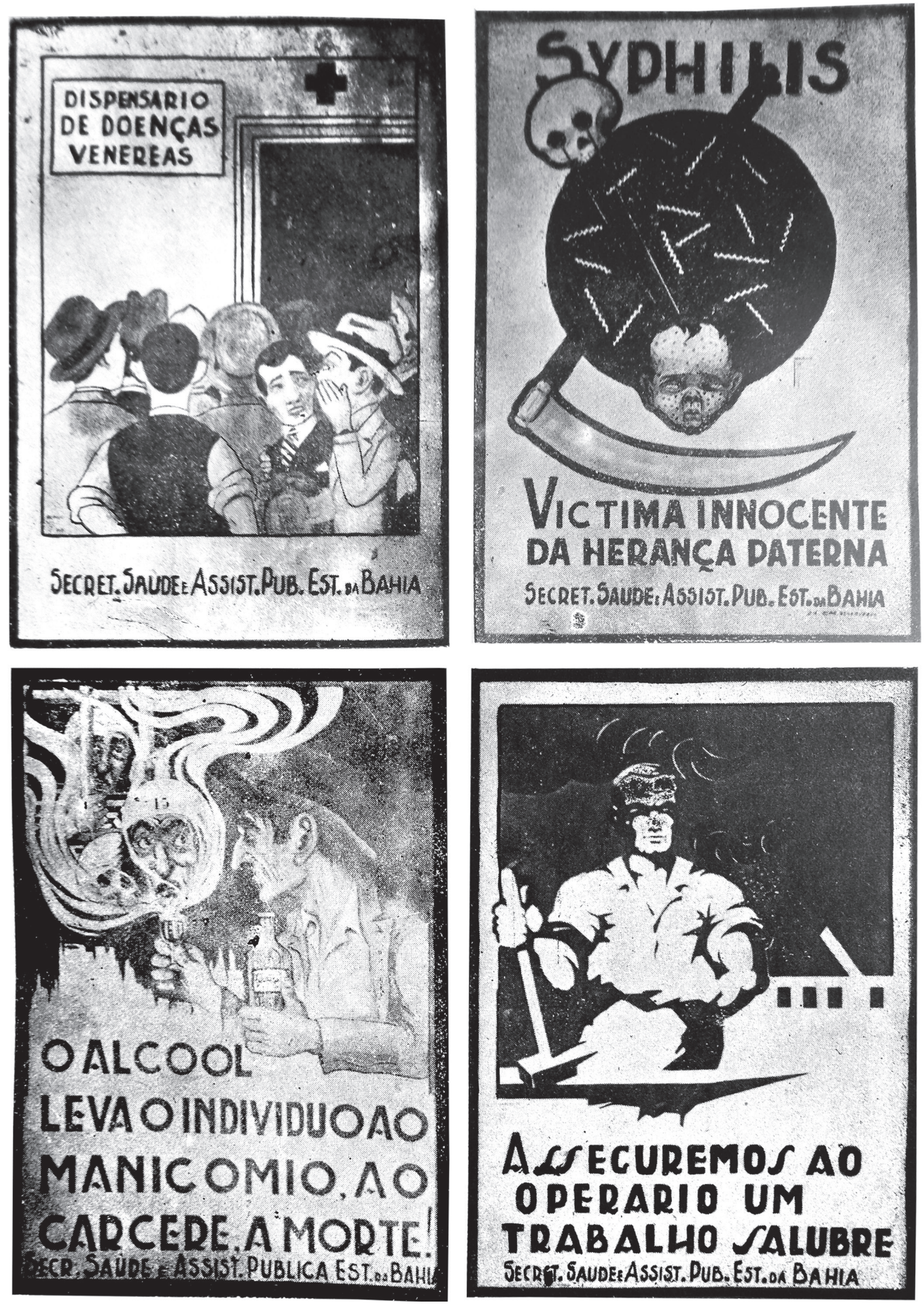

Figura 2: Cartazes de educação sanitária utilizados pela Secretaria de Saúde e Assistência Pública do Estado da Bahia (Barreto, 1928) 

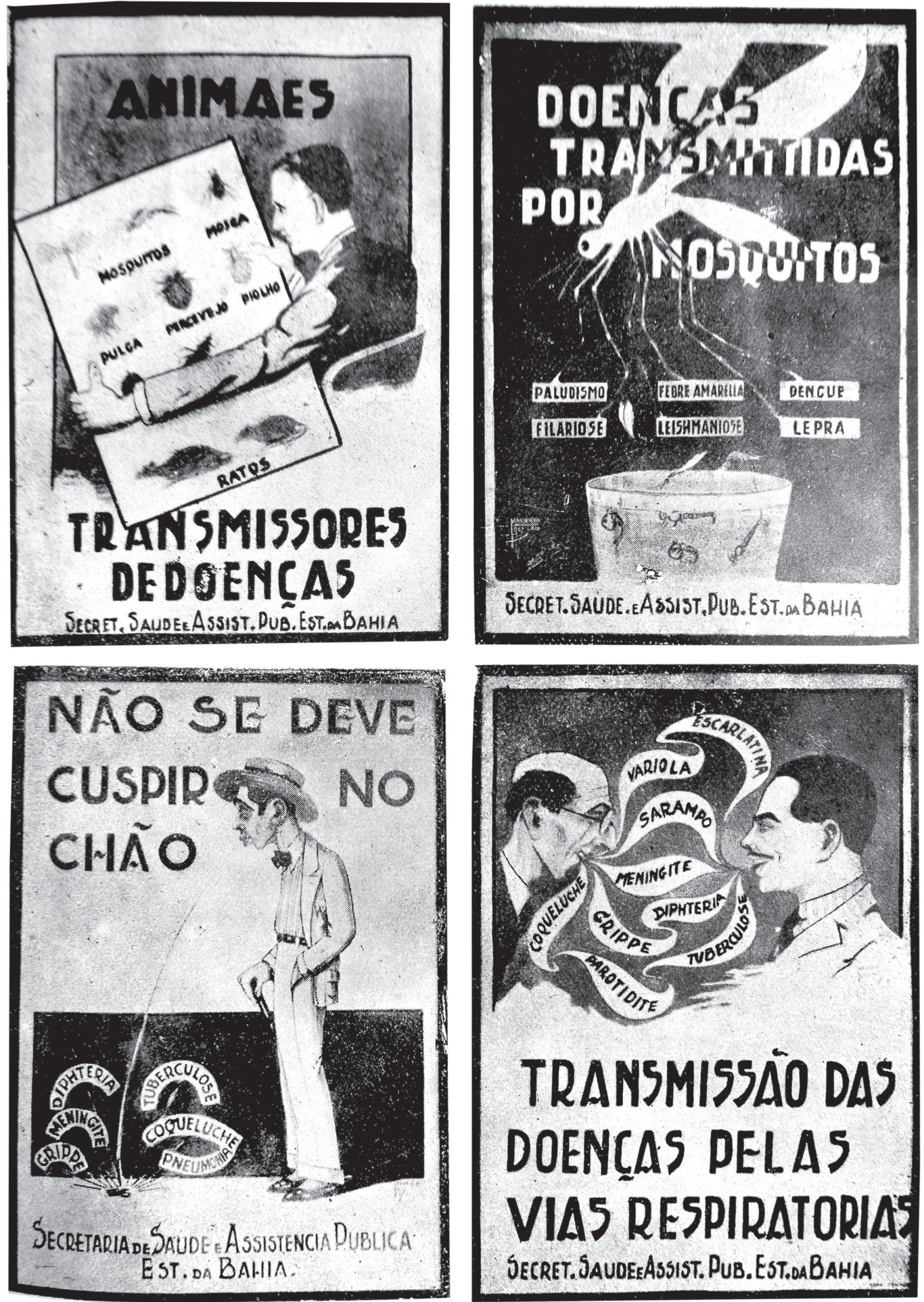

Figura 3: Cartazes de educação sanitária utilizados pela Secretaria de Saúde e Assistência Pública do Estado da Bahia (Barreto, 1928) 

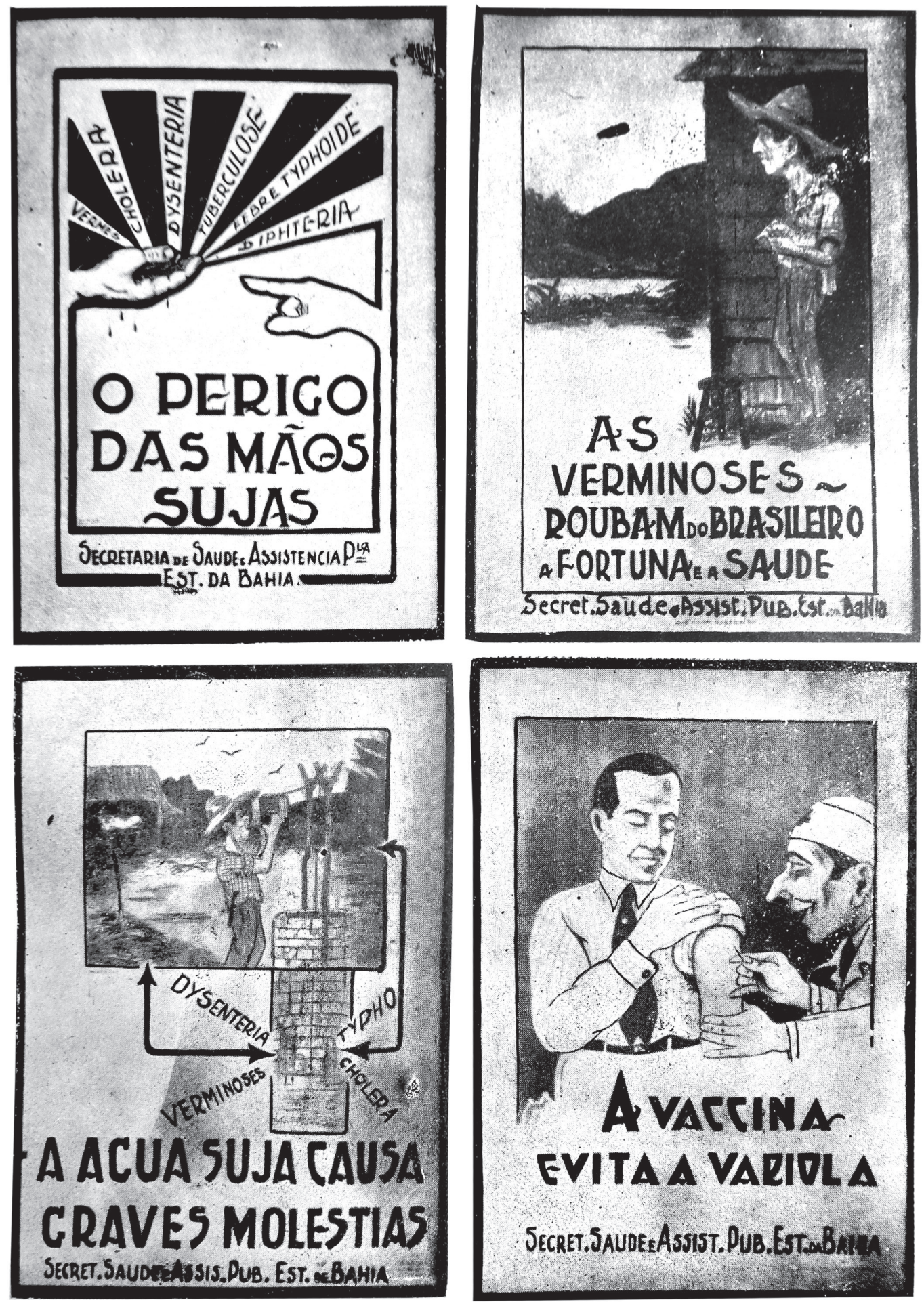

Figura 4: Cartazes de educação sanitária utilizados pela Secretaria de Saúde e Assistência Pública do Estado da Bahia (Barreto, 1928) 
Em relação à higiene industrial, um cartaz exibe a frase "asseguremos ao operário um trabalho salubre", com a imagem de um trabalhador fabril. Outro expressa as mazelas que se acreditavam provenientes do uso do álcool, também relacionado à saúde do trabalhador: "o álcool leva o indivíduo ao manicômio, ao cárcere, à morte". Nessa figura, um homem segura a garrafa de bebida e um copo. Do copo sobe um gás que exibe rostos de pessoas mortas pelo consumo de álcool, para estabelecer uma relação direta entre alcoolismo e óbito. A preocupação com a saúde nas indústrias era expressão da importância que o trabalhador passava a assumir no processo de construção da nação. Ela já estava presente há algum tempo entre as autoridades sanitárias do velho mundo. Desde a virada do século, surgiu na França um grupo de reformadores que se destacavam ao tomar como objeto de atuação o "operário", e não mais o "pobre", anunciando um longo debate sobre a legitimidade do papel do Estado na sociedade industrial (Sanglard, 2008, p.130).

Por fim, alguns cartazes se incumbiam de divulgar os conhecimentos sobre a transmissão vetorial de doenças. Informavam quais delas podiam ser transmitidas por mosquitos, pela saliva ao se cuspir no chão, pelas vias respiratórias, pelas mãos e água sujas. Esse material se relaciona diretamente com o combate de doenças tropicais, a exemplo da febre amarela e da ancilostomíase, alvo da atenção da Fundação Rockefeller. No cartaz com o texto "perigo das mãos sujas", uma mão está ligada a faixas com o nome de doenças: disenteria, tuberculose e febre tifoide. A figura que exibe a frase "as verminoses roubam do brasileiro a fortuna e a saúde" apresenta um morador dos sertões brasileiros na porta de casa, pronto para trabalhar no campo. O cartaz sobre as moléstias causadas pela água suja representa um homem que bebe água direto de uma cisterna. Setas indicam que dentro dela há doenças como verminoses e cólera.

As imagens apresentadas constituem um acervo raro, que auxilia na análise sobre a influência da Fundação Rockefeller em projetos brasileiros. É importante demonstrar como os processos de formação impactaram em ações efetivas, realizadas por toda uma geração de sanitaristas que estiveram nos EUA em busca de conhecimentos. Os capítulos que compõem a história da saúde global também são construídos em experiências nacionais, regionais e locais. Eles revelam uma interconexão sistemática que proporciona o desenvolvimento do campo da saúde.

\section{NOTAS}

${ }^{1}$ Isso não quer dizer que o processo ocorreu de forma impositiva. Estudos contemporâneos destacam a
interação, negociação e diálogo científico entre as autoridades locais e os representantes da Fundação
Rockefeller.
${ }^{2}$ Diferente de outros médicos bolsistas da Rockefeller, que fizeram o curso de Higiene e Saúde Pública em
dois anos, Antônio de Barros Barreto o realizou em apenas um. Já havia cursado disciplinas similares no
Brasil, quando estudante do Curso de Aplicação do Instituto Oswaldo Cruz. Após o primeiro ano, pediu um
segundo ano de bolsa, para poder estudar na França, mas Carlos Chagas não quis solicitar esse privilégio à
International Health Board, e L. Hackett considerou não haver nenhuma vantagem particular na viagem
à Europa (RAC, s.d.).
${ }^{3}$ Sabe-se que, em 1921, a IHB buscava se guiar por critérios universalistas na seleção dos candidatos à
bolsa, mas que a escolha era feita em parceria com médicos e sanitaristas brasileiros (Santos, Faria, 2003,
p.63). No memorial apresentado à Faculdade de Medicina da Bahia, em 1935, expõe-se que o médico
utilizou o prêmio de Viagem de Aluno Laureado, da Faculdade de Medicina da Bahia, para viajar à Europa 
e estudar organizações sanitárias de diversos países como França, Alemanha, Suíça, Bélgica e Itália (cf. Barreto, 1935, p.8). Isso ocorreu diante da inviabilização do financiamento de um segundo ano de bolsa pela Fundação Rockefeller.

${ }^{4}$ Ao longo da sua experiência como bolsista, ele recebeu carta de apresentação para visitar o doutor Ernest P. Boas, do Hospital Montefiore; doutor W.H. Wiley, do Blythewood Sanitarium Greenwich e capitão C.H.T. Loundes, do US Naval Hospital, Brooklyn. Barros Barreto tinha interesse em observar fisioterapia nas instituições mencionadas e também higiene industrial. Por isso, também foi recomendado ao doutor William B. Stone, do Memorial Hospital; C.N. Watson, da American Telephone e Telegraph; Miss Ruth Emory, da NY State Society for Promotion of Occupational Therapy (Cf. RAC, s.d.).

${ }^{5}$ Em 1925 foi criada a Subsecretaria de Saúde e Assistência Pública, transformada em Secretaria de Saúde e Assistência Pública em 1927.

\section{REFERÊNCIAS}

BAHIA.

Poder Legislativo. Lei n.1.811, de 29 de julho de 1925. Organiza a Subsecretaria de Saúde e Assistência Pública. Diário Oficial do Estado da Bahia, 2 ago. 1925.

BARRETO, Antônio Luis Cavalcanti de Albuquerque de Barros.

Currículo. Arquivo Renato Berbert de Castro; Fundo dos Acadêmicos Falecidos, cadeira 5, $2^{\circ}$ titular, biografia, pasta 59 (Academia de Letras da Bahia, Salvador). 18 nov. 1947.

BARRETO, Antônio Luis Cavalcanti

Albuquerque de Barros.

Titulos e trabalhos científicos. Bahia: Imprensa

Oficial do Estado. 1935.

BARRETO, Antônio Luis Cavalcanti

Albuquerque de Barros.

Relatório da Secretaria de Saúde e Assistência Pública: ano de 1927. Bahia: Imprensa Oficial do Estado. 1928.

BARRETO, Antônio Luis Cavalcanti

Albuquerque de Barros.

Relatório apresentado ao Sr. Dr. Diretor pelo Dr. Antônio Luiz C.A. Barros Barreto (Chefe do Serviço). Arquivos Paranaenses de Medicina, ano 5, n.4, p.111-121. 1924.

BARRETO, Antônio Luis Cavalcanti

Albuquerque de Barros.

Educação e propaganda sanitárias: importância na defesa da saúde coletiva. Arquivos Brasileiros de Medicina, ano 13, n.11, p.1203-1207 (Boletim Sanitário do Departamento Nacional de Saúde Pública, ano 2, n.5). 1923a.

BARRETO, Antônio Luis Cavalcanti

Albuquerque de Barros.

Métodos de propaganda sanitária. Arquivos

Brasileiros de Medicina, ano 13, n.11, p.1203-1207

(Boletim Sanitário do Departamento Nacional de

Saúde Pública, ano 2, n.5). 1923b.
BARRETO, Antônio Luis Cavalcanti

Albuquerque de Barros.

Revisão da subfamília Subulurinae Travassos, 1914. Rio de Janeiro: Tipografia Leuzinger. 1918.

BATISTA, Ricardo dos Santos.

Sífilis e reforma da saúde na Bahia (1920-1945).

Salvador: Eduneb. 2017a.

BATISTA, Ricardo dos Santos.

Sífilis e relações de gênero na Bahia. In: Franco, Sebastião Pimentel; Nascimento, Dilene Raimundo; Silveira, Anny Jacqueline Torres (Org.). Uma história brasileira das doenças, v.7. Belo Horizonte: Fino Traço. p.113-132. 2017b.

BATISTA, Ricardo dos Santos.

Um projeto de combate à sífilis nos sertões da Bahia. Intellectus, ano 15, n.2, p.224-241. 2016.

BATISTA, Ricardo dos Santos; SOUZA, Christiane Maria Cruz de.

Sífilis, medicina e organização sanitária em Salvador, BA. In: Mota, André; Marinho, Maria Gabriela S.M.C.; Bertolli Filho, Cláudio (Org.). As enfermidades e suas metáforas: epidemias, vacinação e produção de conhecimento. São Paulo: USP; UFABC; CD.G Casa de Soluções. p.49-69. 2015.

BENCHIMOL, Jaime Larry (Coord.).

Febre amarela: a doença e a vacina, uma história inacabada. Rio de Janeiro: Editora Fiocruz. 2001.

BENCHIMOL, Jaime et al.

Cerejeiras e cafezais: relações médico-científicas entre Brasil e Japão e a saga de Hideyo Noguchi. Rio de Janeiro: Bom Texto. 2009.

BUENO, Eduardo; TAITELBAUM, Paula. Vendendo saúde: história da propaganda de medicamentos no Brasil. Brasília: Anvisa. 2008.

FARIA, Lina.

Os primeiros anos da Reforma Sanitária no Brasil e a atuação da Fundação Rockefeller (19151920). Physis: Revista de Saúde Coletiva, v.5, n.1, p.109-129. 1995. 
FREIRE, Maria Martha de Luna.

Mulheres, mães e médicos: discurso maternalista no Brasil. Rio de Janeiro: Editora FGV. 2009.

HOCHMAN, Gilberto.

A era do saneamento: as bases políticas de saúde pública no Brasil. São Paulo: Hucitec. 2012.

LACERDA, Aline Lopes de.

Retratos do Brasil: uma coleção do Rockefeller Archive Center. História, Ciências, SaúdeManguinhos, v.9, n.3, p.625-645. 2002.

LÖWY, Ilana.

Vírus, mosquitos e modernidade: a febre amarela no Brasil entre ciência e política. Rio de Janeiro: Editora Fiocruz. 2006.

PALMER, Steven.

Gênese da saúde global: a Fundação Rockefeller no Caribe e na América Latina. Rio de Janeiro: Editora Fiocruz. 2015.

RAC.

Rockefeller Archive Center. Barros Barreto, Dr. Antonio Luiz de. Fellowship recorder cards.
Record group 10.2; series MNS (Medical and Natural Sciences), Brazil (Rockefeller Archive Center, New York). s.d.

SANGLARD, Gisele.

Entre os salões e o laboratório: Guilherme Guinle, a saúde e a ciência no Rio de Janeiro, 1920-1940. Rio de Janeiro: Editora Fiocruz. 2008.

SANTOS, Luiz Antônio de Castro; FARIA, Lina Rodrigues.

O ensino de saúde pública no Brasil: os primeiros tempos no Rio de Janeiro. Trabalho, Educação e Saúde, v.4, n.2, p.291-324. 2006.

SANTOS, Luiz Antônio de Castro; FARIA, Lina Rodrigues.

A reforma sanitária no Brasil: ecos da Primeira República. Bragança Paulista: Edusf. 2003.

SILVA, James Roberto.

Doença, fotografia e representação: revistas médicas em São Paulo e Paris, 1869-1925. São

Paulo: Edusp. 2009. 